\title{
Privatization and Employment in Post-Communist Countries
}

\author{
Chang Liu, Yasunori Ishii* \\ Graduate School of Economics, Waseda University, Tokyo, Japan \\ Email: liuchang.aquariud@gmail.com, ${ }^{*}$ yishii@waseda.jp
}

Received 3 June 2014; revised 8 July 2014; accepted 3 August 2014

Copyright (C) 2014 by authors and Scientific Research Publishing Inc.

This work is licensed under the Creative Commons Attribution International License (CC BY). http://creativecommons.org/licenses/by/4.0/

c) (†) Open Access

\begin{abstract}
In this study, by establishing a third-country trade model of an international duopoly where two state firms from different post-communist countries compete against each other, we analyze the effects of a change in the degree of privatization on firms' labor inputs and on the optimal privatization policy in post-communist countries. We show that a rise in the degree of privatization in a country raises labor input, output and exports of that country's firm, while reducing those of the rival firm. Furthermore, we find that either full or partial privatization of state firms could be optimal in post-communist countries.
\end{abstract}

\section{Keywords}

Privatization Policy, State Firms' Labor Inputs, Post-Communist Countries, International Duopoly, Third-Country Trade Model

\section{Introduction}

There have been many studies on the privatization of public firms in capitalist countries. Several pioneering works (De Fraja and Delbono [1], Fjell and Pal [2], and Matsumura [3]) found that the privatization of public firms improves social welfare, and that it is optimal to partially privatize public firms. Furthermore, later studies extended these models in many directions and found several interesting results (see White [4], Payago-Theotoky [5], Kato and Tomaru [6], Matsumura and Tomaru [7], for example).

The above studies, in spite of their remarkable findings, all discussed public firms' privatization in capitalist countries and hypothesized that partially privatized public firms maximize the weighted average of social welfare and profit. However, such a hypothesis seems to be improper when analyzing privatization in post-communist countries. Because countries in the former Communist bloc were administered for workers, it is more

*Corresponding author. 
reasonable to suppose that state firms in those countries acted as labor-managed firms maximizing income per labor. Indeed, Milanovic [8], Pejovich [9] and Lambertini and Rossini [10] found that there were labor-managed firms in Eastern Europe and in the Far Eastern countries. Therefore, in this study, we adopt the hypothesis that partially privatized state firms in post-communist countries maximize the weighted average of profit and income per labor (henceforth, per capita earnings).

Furthermore, in the interests of realism, we emphasize the following two aspects: first, the time lag in state firms' privatization in different countries and second, the rivalry among privatized state firms in international markets. As an example of the first aspect, it considers the time lags between Russia and China in commencing such privatization. The second aspect highlights that many privatized state firms in post-communist countries expanded into international markets. Thus, we consider that the post-communist countries privatized their state firms in an atmosphere of globalization.

The rest of this paper is organized as follows. In Section 2, we set up a model. In Section 3, we investigate how the privatization policies of post-communist countries affect their state firms' labor inputs, as well as these firms' outputs and exports. In Section 4, we analyze the optimal privatization policy of a post-communist country. Section 5 concludes.

\section{The Model and Assumptions}

We consider an international duopoly composed of two state firms from different post-communist countries. One of these countries (henceforth, domestic country) is to implement a privatization policy, and the other (henceforth, foreign country) has already implemented such a policy. Under these privatization policies, these two firms produce homogeneous goods in their countries and export all of them to a third country. Thus, our model is a version of the third-country trade model explored by Brander and Spencer [11].

We assume that labor is the only input in the production process and that both firms' production functions, $x=f(l)$ and $x^{*}=f^{*}\left(l^{*}\right)$, have traditional features, that is, they are strictly increasing and convex (concave) for labor less (more) than $\tilde{l}\left(\tilde{l}^{*}\right)$, where $x\left(x^{*}\right)$ is output (=exports in the third-country trade model), and $l\left(l^{*}\right)$ is labor input (a symbol with a superscript $*$ denotes the corresponding foreign country variable).

The inverse demand function in the third country is given by $p\left(x+x^{*}\right)$ with $p^{\prime}\left(x+x^{*}\right)<0$. Then, profits, $\pi$ and $\pi^{*}$, of the domestic and foreign state firms are defined as $\pi=p\left(x+x^{*}\right) x-w l$ and

$\pi^{*}=p\left(x+x^{*}\right) x^{*}-w^{*} l$, where $w$ and $w^{*}$ are wage rates determined in the domestic and foreign labor markets which are both assumed competitive, respectively. Therefore, income per labor $Y$ in the domestic country is given by $Y=\pi / l+w$, while that in the foreign country is $Y^{*}=\pi^{*} / l+w^{*}$.

When the state firms are completely nationalized, their objective is the same as that of their governments, that is, maximization of income per labor. Thus, domestic and foreign governments' objective functions are respectively defined as

$$
H=Y=\pi / l+w, \quad H^{*}=Y^{*}=\pi^{*} / l+w^{*} .
$$

However, when the state firms are privatized, their objectives become different from those of their governments. Privatized firms' objective is to maximize per capita earnings. The per capita earnings, $V$ and $V^{*}$, of the privatized domestic and foreign state firms are respectively given by

$$
\begin{aligned}
& V=\lambda \pi+(1-\lambda) Y=\{(\lambda+(1-\lambda) / l)\} \pi+(1-\lambda) w, \\
& V^{*}=\lambda^{*} \pi^{*}+\left(1-\lambda^{*}\right) Y^{*}=\left\{\left(\lambda^{*}+\left(1-\lambda^{*}\right) / l^{*}\right)\right\} \pi^{*}+\left(1-\lambda^{*}\right) w^{*},
\end{aligned}
$$

where $\pi=p\left(x+x^{*}\right) x-w l, \pi^{*}=p\left(x+x^{*}\right) x^{*}-w^{*} l$ and $\lambda\left(\lambda^{*}\right)$ represents the degree of privatization of the state firms in the domestic (foreign) country (As regards the definition of the degree of privatization, see Matsumura [3]). Note here that the two models (2) and (3) are not independent because the domestic and foreign firms share the same inverse demand function when defining their per capita earnings. In (2) and (3), while the foreign privatization degree and wage rates are parameters, the domestic privatization degree and two firms' labor inputs are control variables. Thus, the domestic government implements a privatization policy to maximize income per labor in the domestic country, and the two countries' firms choose labor inputs (outputs and exports) to maximize their per capita earnings, respectively. 
We assume that the governments and firms play a two-stage Nash game. In the first stage, only the domestic government chooses its optimal privatization policy because the foreign government's optimal policy is predetermined. In the second stage, the domestic and foreign firms choose their labor inputs (outputs and exports). We use a backward induction method to solve the above problem.

\section{Optimal Labor Input Decisions in the Second Stage}

In the second stage, since the domestic and foreign state firms choose non-cooperatively their labor inputs to maximize per capita earnings, industry equilibrium conditions are given by

$$
\begin{aligned}
& \{(\lambda+(1-\lambda) / l)\} \pi_{l}-(1-\lambda) \pi / l^{2}=0, \\
& \left\{\left(\lambda^{*}+\left(1-\lambda^{*}\right) / l^{*}\right)\right\} \pi_{l^{*}}^{*}-\left(1-\lambda^{*}\right) \pi^{*} / l^{* 2}=0,
\end{aligned}
$$

where (4) and (5) are the firms' first-order conditions for profit maximization, and $\pi_{l}$ and $\pi_{l^{*}}^{*}$ represent $\partial \pi / \partial l$ and $\partial \pi^{*} / \partial l^{*}$, respectively (We use similar abbreviations of differentiations, i.e., $V_{l}=\partial V / \partial l$, $V_{l^{*}}=\partial^{2} V / \partial l^{*} \partial l, V_{l^{*} l^{*}}^{*}=\partial^{2} V^{*} / \partial l^{* 2}$, and so on). We assume that the firms' second-order conditions for maximization and the industry's stability conditions are satisfied:

$$
V_{l l}<V_{l l^{*}}<0, \quad V_{l^{*} l^{*}}^{*}<V_{l^{*} l}^{*}<0
$$

where $V_{l l}=\partial^{2} V / \partial l^{2}, V_{l l^{*}}=\partial^{2} V / \partial l^{*} \partial l, V_{l^{*} l^{*}}^{*}=\partial^{2} V^{*} / \partial l^{* 2}$, and $V_{l^{*} l}^{*}=\partial^{2} V^{*} / \partial l \partial l^{*}$. Then, solving (4) and (5) simultaneously because these equations are not independent, we obtain firms' optimal labor inputs at industry equilibrium in the second stage:

$$
l=l\left(\lambda, \lambda^{*}, w, w^{*}\right), \quad l=l\left(\lambda, \lambda^{*}, w, w^{*}\right) .
$$

Now, totally differentiating the industry equilibrium conditions, (4) and (5), with respect to $l, l^{*}, \lambda$, and $\lambda^{*}$, we get

$$
\left(\begin{array}{cc}
V_{l l} & V_{l^{*}} \\
V_{l^{*} l}^{*} & V_{l^{*} l^{*}}^{*}
\end{array}\right)\left(\begin{array}{c}
\mathrm{d} l \\
\mathrm{~d} l^{*}
\end{array}\right)=\left(\begin{array}{c}
-V_{l \lambda} \mathrm{d} \lambda \\
-V_{l^{*} l^{*}}^{*} \mathrm{~d} \lambda^{*}
\end{array}\right) .
$$

Then, deriving $\partial l / \partial \lambda, \partial l^{*} / \partial \lambda, \partial l / \partial \lambda^{*}$ and $\partial l^{*} / \partial \lambda^{*}$ from (8), and considering (6), $V_{l \lambda}>0$, and $V_{l^{*} \lambda^{*}}^{*}>0$ (see Appendix) into the results, we obtain

$$
\begin{aligned}
& \partial l / \partial \lambda=l_{\lambda}=-V_{l \lambda} V_{l^{*} l^{*}}^{*} / \Delta>0, \quad \partial l^{*} / \partial \lambda=l_{\lambda}^{*}=V_{l \lambda} V_{l^{*} l}^{*} / \Delta<0, \\
& \partial l / \partial \lambda^{*}=l_{\lambda^{*}}=V_{l^{*} \lambda^{*}}^{*} V_{l^{*}} / \Delta<0, \quad \partial l^{*} / \partial \lambda^{*}=l_{\lambda^{*}}^{*}=-V_{l^{*} \lambda^{*}}^{*} V_{l l} / \Delta>0,
\end{aligned}
$$

where $\Delta=V_{l l} V_{l^{*} l^{*}}^{*}-V_{l^{*}} V_{l^{*} l}^{*}>0$. Thus, since a rise (decrease) in labor input raises (reduces) output and export in our model, (9) gives the following proposition:

Proposition 1: A rise in the degree of privatization of the domestic (foreign) country raises the labor input (output and export) of the domestic (foreign) state firm, while it reduces that of the foreign (domestic) state firm, and vice versa.

Proposition 1 is similar to a finding of Matsumura [3] that output of a public firm in a capitalist country increases with its degree of privatization. Furthermore, this proposition implies that the state firm maximizes its labor input (output and exports) when it is completely privatized. It also indicates that while a rise in the degree of privatization in a post-communist country promotes its globalization, it hurts the globalization of its rivals. Therefore, privatization policy in each country offsets different countries' globalization in the international market.

\section{Optimal Privatization Policies in the First Stage}

In the first stage, the domestic government chooses the optimal degree of privatization of its state firm to max- 
imize per capita income, $Y$; the foreign country's privatization policy is predetermined. We assume that $Y$ is strictly concave in $\lambda: Y_{\lambda \lambda}<0$. Then, if $\lambda$ is unbounded, the optimal privatization degree of the domestic government is given by $\lambda$ that satisfies

$$
Y_{\lambda}=\left(\pi_{l} l-\pi\right) l_{\lambda} / l^{2}+\pi_{l^{*}} l_{\lambda}^{*} / l=0 .
$$

However, since $\lambda$ is bounded in the interval $\lambda \in[0,1]$, the value of $\lambda$ derived from (10) is not always the optimal degree of privatization. Hence, let us examine this problem in detail (note that the following arguments are made at equilibrium).

When $\lambda=0$, since $\pi_{l}=\pi / l, \pi_{l^{*}}=p^{* \prime} f^{* \prime} x<0$ and (9) hold from (4) and (5) at industry equilibrium in the second stage, (10) reduces to

$$
Y_{\lambda}=\pi_{l^{*}} l_{\lambda}^{*} / l>0,
$$

which implies that the per capita income in the domestic country is not maximized at $\lambda=0$. Thus, the domestic government would never allow its state firm to be a fully nationalized one.

On the other hand, when $\lambda=1$, considering that $\pi_{l}=0$ holds from (4) at industry equilibrium in the second stage, we obtain

$$
Y_{\lambda}=-\pi l_{\lambda} / l^{2}+\pi_{l^{*}} l_{\lambda}^{*} / l .
$$

Clearly, in (12) the sign of $Y_{\lambda}$ is not determined definitely because the first term is negative and the second is positive. Then, we have

$$
Y_{\lambda} \geq(<) \quad \text { as } \pi \leq(>) \Phi,
$$

at $\lambda=1$, where $\Phi=l \pi_{l^{*}} l_{\lambda}^{*} / l_{\lambda}=l \pi_{l^{*}} V_{l^{*}}^{*} / V_{l^{*} l^{*}}^{*}>0$. Thus, (13) shows that $Y$ increases (decreases) as $\lambda$ rises (falls) when $\pi \leq(>) \Phi$ holds, and vice versa. It follows that the domestic government would have an incentive to privatize its state firm perfectly (partially) when it recognizes that $\pi \leq(>) \Phi$ at industry equilibrium. Therefore, (13) presents the next proposition:

Proposition 2: The optimal privatization policy for a post-communist government is perfect (partial) privatization of its state firm when profit of its fully privatized state firm is not large (large) enough at industry equilibrium.

This proposition says that the post-communist government completely privatizes its state firm when its optimal profit is not large enough at $\lambda=1$, and partially privatizes otherwise. In post-communist countries, any state firm whose maximum profit at $\lambda=1$ falls below a certain critical level can no longer ensure per capita incomes larger than those achievable by a private firm. Therefore, in such circumstances, governments have an incentive to fully privatize their state firms.

\section{Conclusions}

In this study, we analyzed optimal privatization policies and their effects on labor inputs in post-communist countries, assuming that privatized state firms maximize per capita earnings, while their governments maximize per capita income.

We found that full (partial) privatization serves as the optimal privatization policy of the post-communist country when the equilibrium profit of its state firm under perfect privatization is not large (large) enough. Clearly, our finding is contrary to that of Matsumura [3], who found that only partial privatization is optimal for a public firm. However, note that Matsumura derived his result for capitalist countries, while our result holds for post-communist countries.

Moreover, we demonstrated that a rise in the degree of privatization of state firms in post-communist countries raises domestic labor input, output and exports, while reducing those of the rival country. Therefore, in an increasingly globalizing world, governments would do well to set privatization policies after giving due consideration to their international dependencies.

\section{Acknowledgments}

The authors would like to express their gratitude to the Ministry of Education, Culture, Sport, Science, and 
Technology in Japan for its financial support.

\section{References}

[1] De Fraja, G. and Delbono, F. (1989) Alternative Strategies of a Public Enterprise in Oligopoly. Oxford Economic Papers, 41, 302-311.

[2] Fjell, K. and Pal, D. (1996) A Mixed Oligopoly in the Presence of Foreign Private Firms. Canadian Journal of Economics, 29, 737-743.

[3] Matsumura, T. (1998) Partial Privatization in Mixed Duopoly. Journal of Public Economics, 70, 473-483. http://dx.doi.org/10.1016/S0047-2727(98)00051-6

[4] White, M. (1996) Mixed Oligopoly, Privatization and Subsidization. Economics Letters, 53, 189-119. http://dx.doi.org/10.1016/S0165-1765(96)00916-0

[5] Payago-Theotok, J. (2001) Mixed Oligopoly, Subsidization and the Order of Firms Moves: An Irrelevance Result. Economic Bulletin, 12, 1-5.

[6] Kato, K. and Tomaru, Y. (2007) Mixed Oligopoly, Privatization, Subsidization, and the Order of Firms’ Moves: Several Types of Objectives. Economics Letters, 96, 287-292. http://dx.doi.org/10.1016/j.econlet.2007.01.017

[7] Matsumura, T. and Tomaru, C. (2012) Market Structure and Privatization Policy under International Competition. Japanese Economic Review, 63, 244-258. http://dx.doi.org/10.1111/j.1468-5876.2012.00572.x

[8] Milanovic, B. (1991) Privatization in Post-communist Societies. Communist Economies and Economic Transformation, 2, 3-39.

[9] Pejovich, S. (1992) Why has the Labor-managed Firm Failed. Cato Journal, 12, 461-473.

[10] Lambertini, L. and Rossini, G. (1998) Capital Commitment and Cournot Competition with Labor-Managed and Profit-Maximizing Firms. Australian Economics Papers, 37, 14-21. http://dx.doi.org/10.1111/1467-8454.00002

[11] Brander, J. and Spencer, B. (1985) Export Subsidies and International Market Share Rivalry. Journal of International Economics, 18, 83-100. http://dx.doi.org/10.1016/0022-1996(85)90006-6

\section{Appendix: Proof of $V_{l \lambda}>0$}

Partial differentiation of $V_{l}$ with respect to $\lambda$ gives $V_{l \lambda}=\pi_{l}+\left\{(\pi / l)-\pi_{l}\right\} / l$. Thus, considering that $\pi_{l}=\pi / l$ at $\lambda=0$ and $\pi_{l}=0$ at $\lambda=1$, we obtain $V_{l \lambda}=\pi_{l}>0$ at $\lambda=0$ and $V_{l \lambda}=\pi / l^{2}>0$ at $\lambda=1$. Therefore, $V_{l \lambda}>0$ always holds for $\lambda \in[0,1]$. Similarly, we also easily obtain $V_{l^{*} \lambda^{*}}^{*}>0$. 
Scientific Research Publishing (SCIRP) is one of the largest Open Access journal publishers. It is currently publishing more than 200 open access, online, peer-reviewed journals covering a wide range of academic disciplines. SCIRP serves the worldwide academic communities and contributes to the progress and application of science with its publication.

Other selected journals from SCIRP are listed as below. Submit your manuscript to us via either submit@scirp.org or Online Submission Portal.
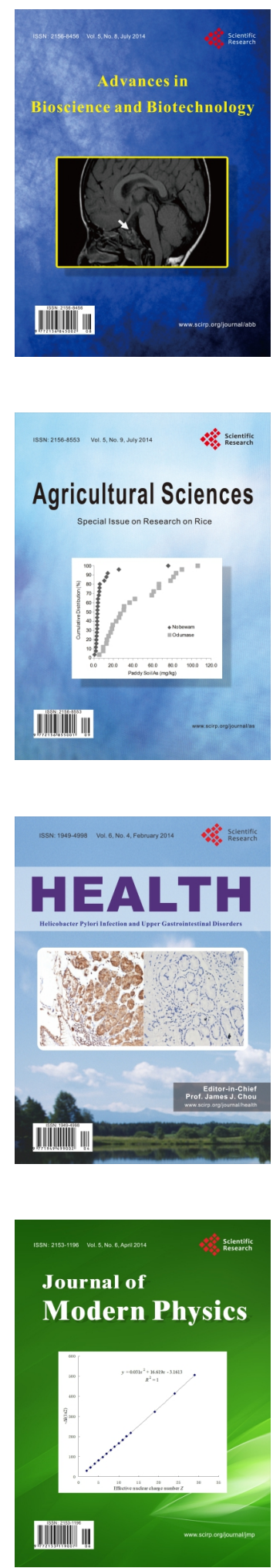
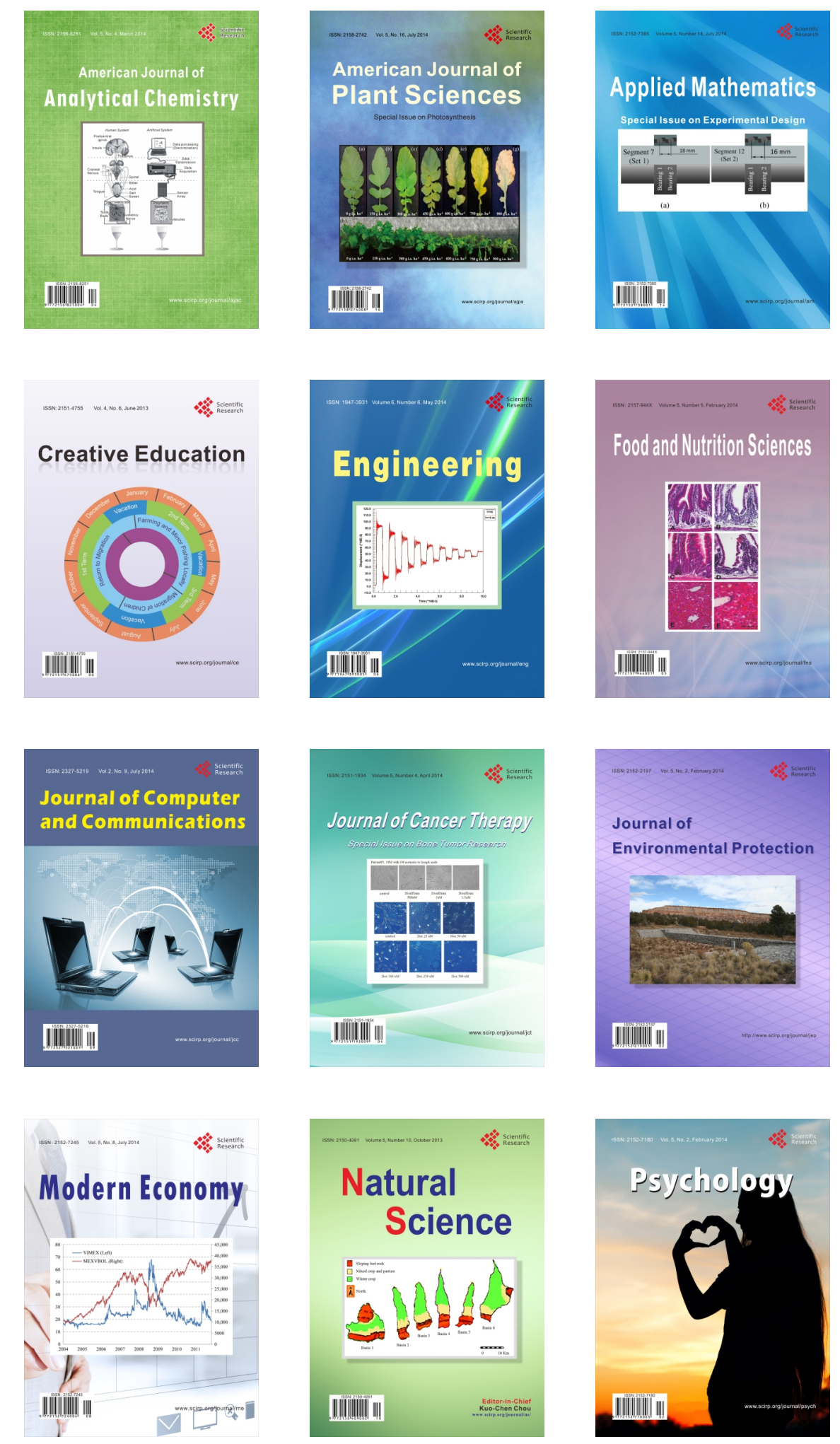